\title{
Industrialización, desarrollo financiero y oferta monetaria en Barcelona a mediados del siglo XIX
}

\author{
Industrialization, financial development and money supply: \\ Barcelona in the mid-nineteenth century
}

\author{
PERE PASCUAL DOMÈNECH \\ CARLES SUDRIÀ TRIAY \\ Centre d'Estudis "Antoni de Capmany", Universidad de Barcelona
}

\begin{abstract}
RESUMEN
El artículo trata de la necesidad, inherente a todo proceso de industrialización, de incrementar la oferta monetaria a fin de evitar tensiones deflacionarias. Se estudia el caso de una importante plaza comercial y financiera: la Barcelona de mediados del siglo XIX. Se precisa el volumen de los diferentes tipos de moneda fiduciaria en circulación (billetes, talones, órdenes de pago, obligaciones...) y sus características como medios de pago. La finalidad del estudio es mostrar que, en un contexto de free banking sin curso forzoso de moneda fiduciaria, existía un proceso automático hacia el equilibrio entre oferta y demanda de dinero, y que cualquier posible exceso de oferta era eliminado por un efecto "expulsión". En dichos sistemas, la expansión de la oferta monetaria no parece tener repercusiones notables sobre los precios; pero, en cambio, sus súbitas contracciones tenían intensos efectos alcistas sobre el tipo de interés.
\end{abstract}

PALABRAS CLAVE: Industrialización, Oferta monetaria, Precios, Tipo de interés, España, Siglo XIX

Códigos JEL: E41, E42, N13, N23

\section{ABSTRACT}

The article deals with the need, inherent in any process of industrialization, to increase money supply in order to avoid deflationary tensions. We examine the case of a major financial and commercial centre: Barcelona in the mid-nineteenth century. The paper specifies the volume of different types of fiat money in circulation (bank notes, "validated" cheques, internal pay orders, short-term bonds...) and their characteristics as means of payment. The aim of the study is to show that, in a context of "free banking" without legal tender of the paper money, there was an automatic process towards a balance between supply and demand for money and that any possible oversupply was eliminated through a "crowding out" effect. In such systems, money-supply growth seems have not significant effects on prices, but instead, sudden contractions of money supply did have intense upward impacts on interest rate.

KEY WORDS: Industrialisation, Money supply, Prices, Interest rate, Spain, $19^{\text {th }}$ Century

JEL Codes: E41, E42, N13, N23 


\section{Introducción 1}

$\mathrm{E}$ n los últimos años, una serie de trabajos tanto teóricos como empíricos han reavivado el viejo debate sobre la relación entre desarrollo financiero y crecimiento económico. Las propuestas avanzadas por Cameron, Goldsmith y Kindleberger, entre otros, en la década de 1960 han encontrado nuevo respaldo así en trabajos de historia financiera como en estudios dedicados a los países que se encuentran actualmente en vías de desarrollo. En el ámbito de la historia financiera, los recientes trabajos de Sylla, Rousseau y Bordo, entre otros, han aportado nuevas evidencias y reivindicado la importancia del desarrollo financiero en las primeras fases de la industrialización ${ }^{2}$. Los economistas del desarrollo, por otro lado, han postulado las mismas hipótesis basándose en estudios sobre los factores del crecimiento económico en los países hoy emergentes ${ }^{3}$. En esta ocasión, historiadores económicos y economistas del desarrollo han conectado sus trabajos y ambas aproximaciones han tendido a reforzarse mutuamente.

Ross Levine, en una síntesis reciente, ha sistematizado las diversas vías por las que el desarrollo financiero influye sobre el crecimiento económico ${ }^{4}$. Señala cinco principales: proveer información ex ante sobre posibles inversiones, controlar la gestión de los fondos prestados una vez realizada la inversión, posibilitar una mejor diversificación y gestión del riesgo, movilizar y mancomunar el ahorro y, finalmente, facilitar el intercambio de bienes y servicios. A los efectos de este trabajo nos interesa especialmente este último apartado. Los bancos, al proveer a la sociedad de medios de pago (billetes, cuentas corrientes, transferencias, etc.), reducen los costes de transacción en los intercambios de bienes y servicios, facilitando la especialización y, en consecuencia, la obtención de economías de escala y la mejora tecnológica. Como señala Levine, la reducción de los costes de transacción no se produce solamente en el momento en que las economías introducen la moneda, sino que puede continuar posteriormente como consecuencia de subsiguientes innovaciones financieras ${ }^{5}$.

[Fecha de recepción del original, noviembre de 2007. Versión definitiva, marzo de 2008]

1 Este trabajo se inscribe en el proyecto de investigación SEJ2005-02869/ECON financiado por el Ministerio de Educación y Ciencia. Algunos de los datos y referencias utilizados en este artículo proceden de trabajos conjuntos con Yolanda Blasco, a quien agradecemos su colaboración y ayuda. También agradecemos las sugerencias de los evaluadores anónimos de Investigaciones de Historia Económica.

Rousseau y Sylla (2003) y (2006); y Bordo y Rousseau (2006).

King y Levine (1993); y Beck, Levine y Loayza (2000). Véase Levine (2005) para una revisión general de la literatura.

Levine (2005).

Levine (2005), p. 880. 
El presente trabajo pretende ofrecer un análisis de los aspectos monetarios del proceso de modernización financiera que se dio en Cataluña en el segundo tercio del siglo XIX. El caso de Cataluña y, en particular, el de Barcelona, resulta interesante porque en ese período estuvieron simultáneamente en el mercado diversos activos monetarios que presentaban características marcadamente distintas entre sí. El análisis permitirá observar cómo quedaba afectado cada uno de ellos por las fluctuaciones en la demanda de dinero y cómo reaccionaba el público en cada circunstancia.

Antes de entrar en ello, es conveniente introducir algunos elementos de contexto. Es bien sabido que la economía catalana experimentó en los años de nuestro estudio un crecimiento notable, acompañado de cambios estructurales de importancia. Se trata del período central de la primera industrialización, cuyos ejes fueron el desarrollo de la industria algodonera y la construcción de la red ferroviaria ${ }^{6}$. Como es natural, el proceso implicó un incremento de las transacciones que debió de ser, indudablemente, mucho más intenso que el propio crecimiento del producto total, puesto que aumentó el grado de mercantilización de la economía. Por otro lado, hay que tener en cuenta que fábricas y ferrocarriles se financiaron en su práctica totalidad con recursos internos catalanes, con lo que no se contó por esa vía con la entrada de numerario del exterior ${ }^{7}$. Nos hallamos pues, sin duda, en un período de incremento notable de la demanda de dinero.

Una segunda observación debe referirse a la percepción que tenían los contemporáneos de los beneficios que podían derivarse de las innovaciones financieras de carácter monetario. En 1816, Eudald Jaumeandreu, titular de la cátedra de economía política instaurada por la Junta de Comercio, incorporaba a su libro de texto de referencia las ideas sobre la moneda divulgadas por Adam Smith: "Usando el papel en lugar de una gran porción de oro y plata, la sociedad se halla en estado de convertir una gran parte de este fondo estancado en un capital activo, fecundo y productivo para ella. Sin el auxilio del papel el comerciante se ve precisado a tener una porción de sus fondos sin destino y en dinero contante (...), y por lo mismo es para él así como para la sociedad un capital muerto..." 8 . Pero, en caso de no existir un marco legal que impusiera su curso forzoso — proseguía Jaumeandreu-, el dinero fiduciario (o de confianza $)^{9}$ únicamente era admitido por el público si se garantizaba su convertibilidad "a la vista" en moneda con valor intrínseco. Así pues, cuando se dieron

$6 \quad$ Nadal (1992), cap. 3; Pascual (1990); y Maluquer (2001).

7 Sobre la inversión en términos generales, véase Sudrià (1994); sobre los ferrocarriles, Pascual (1999).

8 Jaumeandreu (1988(1816)), pp. 190-195. En la obra de Lluch (1973, pp. 259-332) existe un amplio análisis sobre las fuentes intelectuales y los contenidos del ideario de Jaumeandreu.

9 La expresión procede de Jaumeandreu (1836, p. 254), quien precisó que los billetes de banco "se llaman de confianza, porque mientras el banco conserva su crédito, se admiten voluntariamente en los pagos, como si fuesen dinero...". 
las circunstancias para la introducción del papel moneda, los medios mercantiles barceloneses eran conocedores de sus características y de sus ventajas.

Después de esta introducción, el trabajo se estructura de la siguiente forma. Se estudian, primero, las características de los distintos componentes de la oferta monetaria; se analizan después las relaciones entre oferta y demanda de dinero o, en otras palabras, la "plasticidad" de la oferta ante las fluctuaciones de la demanda; y se concluye, finalmente, con algunas consideraciones de carácter general que pueden extraerse de la experiencia catalana.

\section{Los componentes de la oferta de moneda fiduciaria}

La cristalización de un nuevo sistema comercial externo hizo posible que la balanza de pagos catalana se saldara con crecidos superávit durante el segundo tercio del siglo XIX. Esto se tradujo en un flujo de "onzas" de oro americanas que fueron fundidas y emitidas con cuño español en la casa de la moneda de Barcelona, que actuó bajo el amparo de la Diputación de la provincia. La ceca barcelonesa adoptó unas tarifas de adquisición de pastas sensiblemente superiores a las impuestas por la reforma monetaria de 1824, que determinaron que las cecas gubernamentales de Madrid y Sevilla acuñaran, entre 1824 y 1847, volúmenes de moneda con valor intrínseco extremadamente exiguos ${ }^{10}$.

Esto contribuyó a suministrar medios de cambio a la economía catalana en rápida expansión y a frenar, por tanto, la intensa tensión deflacionaria que el país venía experimentando desde 1817. La existencia en manos del público —a partir de comienzos de la década de 1840 - de un volumen de moneda con valor intrínseco (básicamente de oro) relativamente cuantioso era una condición indispensable para garantizar la convertibilidad y poder plantear la formación de un banco emisor en Barcelona. La disponibilidad de este instrumento había de facilitar el incremento de la oferta monetaria a costes desdeñables y acabar así de modo definitivo con la pesadilla de la deflación.

\subsection{Los billetes del Banco de Barcelona}

La constitución del Banco de Barcelona se aprobó por Real Decreto de 1 de mayo de 1844, después de un par de años de gestiones. El proyecto de formación del banco se

$10 \quad$ Véase Pascual (2004), pp. 57-100. 
gestó en los círculos de la oligarquía comercial y financiera barcelonesa. El amplio apoyo que mereció esta iniciativa entre la clase mercantil e industrial de la ciudad respondía a la necesidad de disponer de un instrumento que posibilitara el depósito de fondos coyunturalmente inactivos y que generara una oferta crediticia en buenas condiciones $^{11}$. En definitiva, el gran objetivo del banco, además de facilitar medios de pago, fue abaratar el precio del dinero ofrecido en operaciones de descuento y de crédito con garantía de mercancías o valores. Es decir, su función era la de paliar las frecuentes tensiones alcistas del tipo de interés, sistemáticamente aprovechadas por los prestamistas que operaban en la plaza para imponer condiciones casi usurarias. En opinión de Laureano Figuerola, el expresado objetivo se alcanzó de manera relativamente satisfactoria. En 1849 afirmaba:

“...el descuento más elevado del Banco asciende al 6 por ciento. Estaba antes estacionado en el 5, y oscila entre este número y el 4 por ciento en los actuales días. Pocas plazas en España pueden alquilar capitales a tan bajo precio, y es necesario reconocer que el Banco habrá contribuido a acercarse al nivel de países mas afortunados, limitando la renta vejatoria exigida por algunos logreros..."12.

El banco contó con más de quinientos clientes clasificados, pero el beneficio de su oferta crediticia tuvo un alcance bastante limitado debido a que practicó una política comercial caracterizada por la prudencia. En la filosofía del banco primó la seguridad sobre cualquier otro tipo de consideración: tanto la aceptación de letras al descuento como el acceso al crédito sobre mercancías o valores requerían garantías personales y subsidiarias muy sólidas. Por otro lado, sus estatutos establecían que todas las operaciones de crédito debían realizarse a un máximo de cuatro meses de plazo. El tipo de interés aplicado se mantuvo, en mayor o menor grado, por debajo del que imperaba en el mercado, en coherencia con las mayores garantías exigidas ${ }^{13}$.

En la afirmación de esta política de prudencia desempeñó un papel importante el grave trastorno que experimentó el banco entre febrero y abril de 1848 cuando, agobiado por un pánico derivado de la revolución francesa de ese año, evitó la quiebra mediante una ampliación de capital realizada en circunstancias críticas. Este contratiempo determinó que los dirigentes del banco decidieran limitar la concesión

11 Sobre la formación de dicho banco, véase Cabana (1978), pp. 9-31; Blasco (2001), pp. 279-312; y Blasco y Sudrià (en prensa). Para un estudio de carácter más general sobre la formación y desarrollo del sistema bancario catalán, Sudrià (1982), pp. 137-176.

12 Figuerola (1983 (1849-1851)), p. 217. Esta obra de Figuerola fue publicada en fascículos entre 1849 y 1851 , y, según Antón Costas, quedó inacabada porque su autor no desarrolló en su totalidad el plan inicialmente previsto.

13 Blasco y Sudrià (en prensa). 
de créditos bajo la garantía de depósitos de mercancías — sobre todo algodón en rama, pero también productos coloniales y metales preciosos-, debido a que se evidenció que dichas garantías resultaban irrealizables en momentos de crisis a causa del simultáneo colapso de los mercados. En lo sucesivo, este tipo de préstamos se reconvirtieron en descuentos de warrants, bajo condiciones mucho más restrictivas, y el banco se especializó en las operaciones más típicas y tradicionales de la banca comercial: el descuento de efectos, el préstamo bajo garantía de depósito de valores mobiliarios y el giro de caudales entre Barcelona y otras plazas. Paralelamente, renunció a sus anteriores proyectos de establecer sucursales en diversas poblaciones del Principado y de las Baleares ${ }^{14}$.

El Cuadro 1 recoge las principales partidas del pasivo de la entidad. Como puede comprobarse, hubo dos etapas bien distintas. Hasta 1866 el nivel de actividad se mantuvo en unos recursos ajenos situados en torno a los 17 millones de pesetas y una tendencia ligeramente expansiva en lo referente a los recursos totales. A partir de 1866 las cifras se disparan y el Banco aumenta tanto sus recursos propios como los ajenos de forma muy notable. Sin embargo, si atendemos a la distribución de los últimos, la cifra global estable anterior a 1866 encubre situaciones muy cambiantes. Estas variaciones tuvieron que ver, en gran parte, con los cambios acaecidos en la regulación bancaria dictada por los distintos gobiernos.

Efectivamente, el volumen de billetes que el Banco de Barcelona tuvo en circulación hasta 1874 —año en el que se concedió el monopolio de emisión al Banco de España ${ }^{15}$ - experimentó diversas alternancias (Gráfico 1). En los primeros meses de su existencia se registró una rápida expansión que quedó truncada a raíz de la crisis de 1848 y de la posterior legislación restrictiva aprobada por el gobierno moderado. La ley de 4 de mayo de 1849 redujo severamente la capacidad de emisión del Banco. Sus estatutos fundacionales cifraban el tope de emisión ordinaria en el monto del capital nominal, mientras la nueva ley lo hacía en el del capital efectivo ${ }^{16}$. Dada la política seguida por el banco de mantener normalmente sólo un 25 por 100 del nominal desembolsado, la nueva norma implicaba reducir la capacidad de emisión de 5 a 1,25 millones de pesetas. Tras la forzada reducción, el monto de billetes en circulación se mantuvo estancado en este nivel hasta $1855^{17}$. No obstante, esta reducción cir-

\footnotetext{
14 Blasco y Sudrià (en prensa).

15 Tortella (1970), pp. 285-287; y Anes (1974), pp. 125-134.

16 La propia ley establecía el límite de emisión para el Banco de San Fernando en la mitad de su capital efectivo (Art. 2). Este límite fue ampliado por la Ley de 15 de Diciembre de 1851 al total del capital efectivo (Art. 7).

17 En el curso del bienio de 1853-1854, la cuantía de los billetes emitidos por el Banco de Barcelona se cifró en 1,25 millones de pesetas, en tanto que el Banco de San Fernando, de Madrid, tenía en circulación 30 millones de pesetas (Tedde, 1999, p. 251).
} 


\section{CUADRO 1}

EVOLUCIÓN DE LOS RECURSOS PROPIOS Y DE LOS RECURSOS AJENOS

DEL BANCO DE BARCELONA, 1845-1874

(promedios semestrales en pesetas)

\begin{tabular}{llcccc}
\hline & $\begin{array}{c}\text { Recursos } \\
\text { propios } \\
\text { (capital y } \\
\text { reservas) }\end{array}$ & $\begin{array}{c}\text { Billetes en } \\
\text { circulación }\end{array}$ & $\begin{array}{c}\text { Cuentas } \\
\text { corrientes } \\
\text { y depósitos }\end{array}$ & Total & $\begin{array}{c}\text { Recursos } \\
\text { propios } \\
\text { y ajenos }\end{array}$ \\
\hline $\mathbf{1 8 4 5 - 1 8 4 9}$ & 2.159 .223 & 4.406 .894 & 3.560 .724 & 7.967 .618 & 10.126 .841 \\
$\mathbf{1 8 5 0 - 1 9 5 4}$ & 1.506 .854 & 1.714 .295 & 14.325 .805 & 16.040 .100 & 17.546 .954 \\
$\mathbf{1 8 5 5 - 1 8 5 9}$ & 4.600 .811 & 6.178 .845 & 11.448 .548 & 17.627 .393 & 22.228 .203 \\
$\mathbf{1 8 6 0 - 1 8 6 4}$ & 5.865 .401 & 10.163 .495 & 6.233 .628 & 16.397 .123 & 22.262 .524 \\
$\mathbf{1 8 6 5 - 1 8 6 9}$ & 8.247 .794 & 18.126 .348 & 17.647 .874 & 35.774 .221 & 44.022 .015 \\
$\mathbf{1 8 7 0 - 1 8 7 4}$ & 8.725 .704 & 19.979 .011 & 32.614 .817 & 52.593 .828 & 61.319 .532 \\
\hline
\end{tabular}

${ }^{*}$ ) 1870-1874 no incluye el último semestre de 1874.

Fuentes: Arxiu Nacional de Catalunya (ANC, en adelante), Fons Banc de Barcelona (BB, en adelante), Memorias del Banco de Barcelona; y Blasco y Sudrià (en prensa).

cunstancial de la oferta monetaria se vio compensada, con creces - como veremos en el siguiente apartado-, por la enorme suma de billetes que puso en circulación en 1852 la Junta de Moneda de Cataluña.

La ley de bancos progresista de 1856 cambió este estado de cosas, ya que situó el tope de emisión en el triple del capital desembolsado. Dado que el banco amplió su capital efectivo de 1,25 a 5 millones entre 1855 y 1856, la capacidad de emisión alcanzó los 15 millones de pesetas. La entidad pudo así compensar el retroceso de los saldos de las cuentas corrientes y depósitos, derivado del aumento de la competencia en la plaza, mediante el incremento de la cantidad de billetes en circulación ${ }^{18}$.

El crac bursátil y la profunda crisis bancaria de 1866 — que determinó la quiebra y liquidación de dos cajas de descuento y de tres sociedades de crédito barcelonesas-

18 Sin embargo, la proliferación de billetes emitidos por otras entidades hizo que el banco tuviera dificultades para alcanzar el tope máximo de emisión permitido por la ley. Véase Blasco y Sudrià (en prensa).

19 Sánchez-Albornoz (1977), pp. 111-122; Pascual (1990), pp. 292-303; y Navas y Sudrià (en prensa). 


\section{GRÁFICO 1}

BILLETES EN CIRCULACIÓN DEL BANCO DE BARCELONA, 1845-1874

(millones de pesetas)

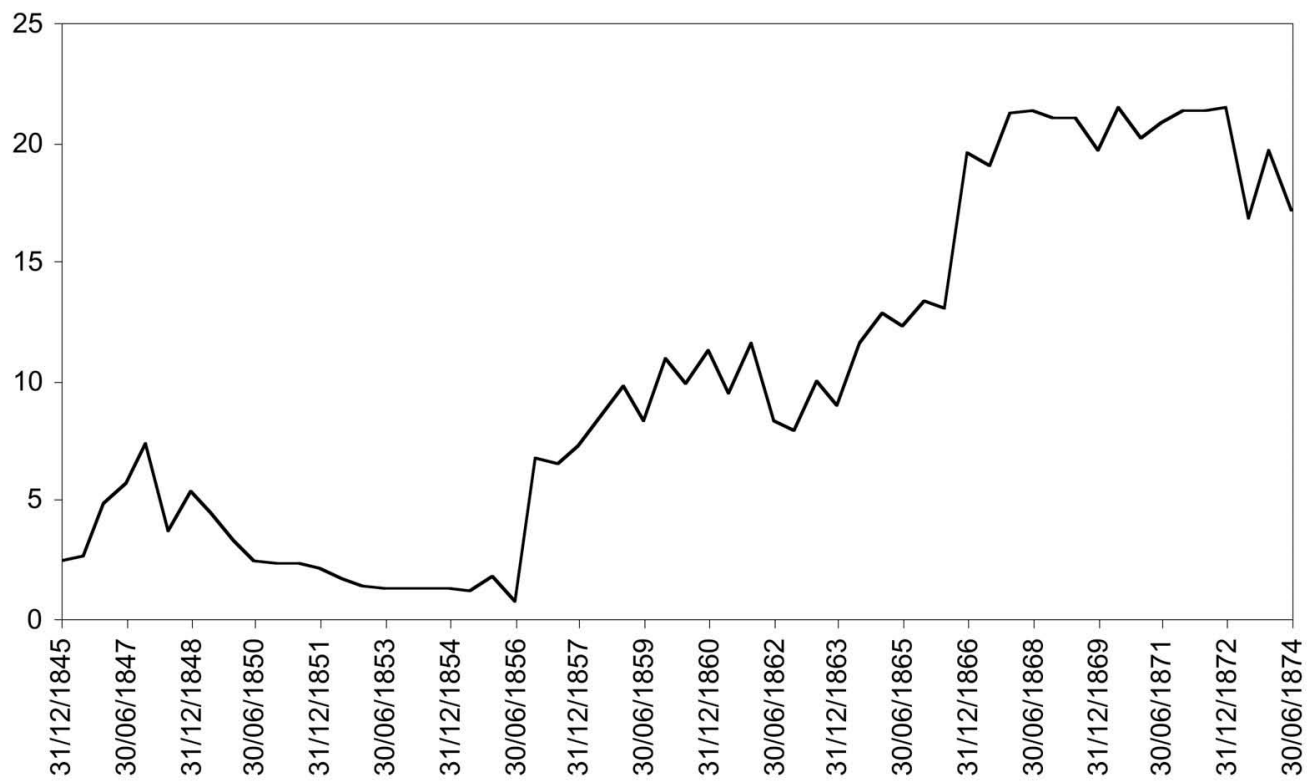

Fuentes: Memorias del Banco de Barcelona, 1845-1874.

cambiaron radicalmente el panorama financiero ${ }^{19}$. Los billetes en circulación del Banco de Barcelona experimentaron un súbito y considerable incremento, ya que vinieron a sustituir de forma forzosa a los diversos activos monetarios emitidos a partir de 1856 por las cajas y las sociedades de crédito —órdenes de pago, talones de caja, obligaciones al portador...-, que circularon por Barcelona en competencia con los billetes del banco emisor ${ }^{20}$. Volveremos a ello más adelante. Desde el fin de la crisis hasta 1874, la circulación de billetes se mantuvo estable en torno a los 21 millones de pesetas. 


\subsection{Los billetes de calderilla catalana}

Las grandes emisiones de calderilla catalana —de carácter acusadamente "nominalista", dada la abismal diferencia entre el coste del metal y el valor nominal atribuido a las monedas - efectuadas durante la Guerra de la Independencia, el Trienio Liberal y por la Diputación de Barcelona en el curso del período 1836-1847 acabaron por provocar un agobiante problema monetario en Cataluña. La calderilla catalana acuñada entre 1810 y 1847 se cifró en 10.147.841,5 pesetas. A ella cabe añadir la que puso en circulación la administración afrancesada entre 1809 y 1814, otras 920.295,6 pesetas. Los cuantiosos beneficios obtenidos se utilizaron, primero, para contribuir a financiar los diferentes episodios bélicos y, entre 1842 y 1847, para sufragar los déficit presupuestarios de la Diputación y del municipio barceloneses, y también para subvencionar la acuñación de moneda con valor intrínseco en la ceca controlada por la corporación provincial ${ }^{21}$.

La acuñación excesiva de moneda de cobre de bajísimo contenido metálico implicó que la calderilla catalana experimentara, durante la década de 1840, una creciente depreciación respecto a su paridad de cambio con la moneda de oro y de plata. En esta época, existía en toda España un exceso de calderilla en circulación, pero dicho problema era, sin duda, más grave en Cataluña que en el resto del país y tenía unas características específicas. El bajo contenido de cobre de la calderilla catalana (en relación a la española) propició que la falsificación adquiriera proporciones alarmantes $^{22}$. En cualquier caso, la moneda de cobre se depreció y esto ocasionó perturbaciones en las relaciones establecidas entre las diferentes monedas integrantes del sistema monetario e implicó el enrarecimiento de la circulación de moneda de oro y de plata ${ }^{23}$. El gobierno intentó enfrentar el problema mediante el decreto de 27 de junio de 1852. El objetivo era frenar el atesoramiento de la moneda con valor intrínseco y la consiguiente "extracción del reino de moneda de oro y plata..."; acabar con "el engaño que sufren los operarios en la determinación del precio de sus jornales, porque satisfechos en cobre no representan en realidad la cantidad de objetos adquiribles..."; y evitar la pérdida que experimentaban "los capitales que son fruto de

$21 \quad$ Pascual (2004), p. 97.

22 La calderilla que se acuñó en Cataluña entre 1808 y 1847 tenía un contenido metálico muy inferior al de la emitida en las otras casas de moneda españolas, por lo que el señoreaje obtenido de su emisión era, por tanto, muy superior. Figuerola (1983 [1849-1850], p. 219) estima que fabricar una pieza de 6 cuartos costaba 4,85 maravedís y su valor nominal era de 24 . El hecho de tratarse de una calderilla tan acusadamente nominalista (casi fiduciaria) ocasionó que la "falsificación ha hecho rápidos progresos en todos los puntos que tienen inmediatas relaciones con Cataluña...".

23 Por lo que respecta a la situación monetaria en estos años, véanse Sardá (1948), pp. 99-129; Raventós (1938), pp. 55-76; y Fernández y Anes (1970), pp. 157-160. 
ahorros hechos en cobre por los jornaleros..."24. Pero en lugar de retirar de la circulación una parte de la moneda de cobre, el gobierno se inclinó por una solución más barata, consistente en establecer medidas tendentes a impedir la competencia entre la moneda de cobre y la de oro y de plata, que se concretaron en limitar la admisión de la primera en el pago de impuestos y en todo tipo de transacciones ${ }^{25}$.

La elevadísima depreciación que afectaba a la calderilla catalana hacía insuficientes las prescripciones del decreto que acabamos de citar. Se hacía indispensable un tratamiento específico, que fue finalmente acordado por Real Decreto de 5 de agosto de 1852. Esta norma estableció la constitución de una Junta de Moneda - presidida por el capitán general e integrada por representantes de las Diputaciones catalanas e instituciones económicas del Principado (Junta de Comercio, Instituto Industrial, etc.) - que se había de responsabilizar de retirar la totalidad de la calderilla catalana en circulación, la cual dejaría de tener curso legal ${ }^{26}$. La administración del Estado anticipó la calderilla española necesaria para cambiar la moneda de cobre catalana a razón de un máximo de 80 reales por familia, que recibiría "en el acto el valor íntegro actual de la moneda catalana en moneda de cobre castellana..."; aun cuando se dejó a criterio de la Junta la posibilidad de excluir del cambio en metálico "a los cabezas de familia (...) pertenecientes a las clases más acomodadas...". La calderilla catalana restante en poder de personas físicas o jurídicas había de ser retirada a cambio de unos vales "por todo el valor nominal de la calderilla que entregue...", emitidos con unos valores de 60, 100, 200, 500 y 1.000 reales, que sólo tendrían curso legal en Cataluña y que serían de admisión forzosa hasta el límite de un 20 por 100 (posteriormente reducido al 10 por 100) del importe de todos los pagos y transacciones. En un futuro inmediato, se preveía sustituir este papel por billetes a fin de evitar posibles falsificaciones y, posteriormente, éstos habían de ser progresivamente amortizados. El gobierno se comprometió a contribuir "con igual suma que las cuatro provincias de Cataluña reunidas para la amortización anual de los billetes

24 Preámbulo del Real Decreto de 27 de junio de 1852, Diario de Barcelona, 186 (4/VII/1852), pp. $3947-3948$.

25 En suma, dicho decreto estableció que: 1) las oficinas de Hacienda sólo admitirían en moneda de cobre un 20 por 100, como máximo, del importe total de los cobros efectuados hasta 31 de diciembre de 1852, porcentaje que se reduciría a un 10 por 100 durante el primer semestre de 1853, a un 5 por 100 en el transcurso del segundo semestre de dicho año y, finalmente, a un 3 por 100 a lo largo del primer semestre de 1854; 2) a partir del 1 de julio de 1854, la moneda de cobre sólo se podría utilizar sin limitaciones en las transacciones de un importe inferior a 20 reales, mientras que la admisión forzosa de dicha moneda quedaría regulada, por lo que respecta a las operaciones que sobrepasasen esta suma, por un sistema de proporción decreciente en función del aumento de la magnitud de las transacciones.

26 Véase Pascual (2007), pp. 184-194. Tanto el pionero estudio de Raventós como el posterior de Fernández y Anes contienen referencias a la cuestión planteada por el exceso de calderilla y, particularmente, a la problemática existente en Cataluña debido a la desbordante masa de moneda de cobre existente en circulación. 
hasta su extinción..."; y la Junta de Moneda quedó encargada de proponer la distribución y recaudación de la suma correspondiente a las Diputaciones catalanas ${ }^{27}$.

En cumplimiento de esta disposición, la Junta de Moneda de Cataluña organizó el cambio masivo de la moneda de cobre catalana por calderilla española en piezas de 8 y de 4 maravedís, que tuvo lugar en todos los municipios del Principado durante los días 22, 23, 24 y 25 de octubre de $1852^{28}$. El gobierno aportó un millón de duros en calderilla para efectuar el cambio, aun cuando, según manifestó la Junta de Moneda poco después de finalizar el proceso, únicamente se emplearon entre 4 y 4,25 millones de pesetas. Una vez terminada esta insólita operación, se constató que se habían tenido que poner en circulación, además, "vales" provisionales por un valor nominal de 9.212.115 pesetas. Por tanto, si agregamos dicha cantidad a las 4.250 .000 pesetas que, aproximadamente, se utilizaron en la operación de cambio en metálico, tenemos que el total de calderilla catalana retirada de la circulación alcanzó una suma superior a 13,46 millones de pesetas. La moneda de cobre catalana acuñada entre 1810 y 1847 tenía un valor nominal de 10.147.841,5 pesetas —o, como máximo, de 11.068.137,2 pesetas en caso de contabilizar la calderilla puesta en circulación durante el período de 1809-1814 por el gobierno afrancesado- - Si tenemos en cuenta que, durante estos años, una parte considerable de esta masa monetaria debió de desaparecer por efecto del desgaste a que estaba sujeta como consecuencia de su elevada velocidad de circulación, todo parece indicar que se amortizaron cantidades considerables de calderilla falsa ${ }^{29}$.

Diario de Barcelona, 237 (4/VIII/1852), pp. 5046-5048. El contenido de este decreto fue expuesto y comentado por Raventós (1938), pp. 65-67.

Los responsables directos del cambio fueron los ayuntamientos del Principado y se efectuó mediante la instalación de mesas en lugares estratégicos de las urbes importantes —en Barcelona se instalaron 88 mesas, o en la casa consistorial en los pequeños pueblos, a la vez que, en previsión de posibles alteraciones del orden público y actuaciones especulativas, el capitán general publicó un bando por el que declaró el estado de sitio y advirtió que pasarían a disposición de tribunales militares aquéllos que "cerrasen sus establecimientos, encareciesen los artículos de primera necesidad, aumentaren el premio o descuento de los cambios, pusieren obstáculos infundados a la circulación de la moneda de cobre y se denegaren a la admisión de abonarés...". Arxiu de la Diputació de Barcelona (ADB, en adelante), legajo 183, Actas de la Excma. Junta de Moneda de Cataluña, sesión de 21 de septiembre de 1852.

Pero, al margen de dicha circunstancia, la normalidad que caracterizó estas actuaciones sorprendió, al parecer, a los mismos responsables, ya que la Junta de Moneda se felicitaba — en un comunicado dirigido a la población el 10 de noviembre de 1852- que un "suceso tan extraordinario que afectaba a todas las clases y fortunas y del cual tan raros ejemplos presenta la historia..." se hubiese realizado sin ningún tipo de complicación (ADB, legajo 183, Actas..., sesión de 8 de noviembre de 1852). Los integrantes de la Junta de Moneda variaron en el transcurso del tiempo debido a que las instituciones representadas designaron diferentes delegados para asistir a las reuniones. Poco después de su constitución, asistían a las sesiones de la misma —además del capitán general y del gobernador de Barcelona - el superintendente de la casa de la moneda de Barcelona, Francesc Paradaltas y Pintó, Josep Parladé, Tomàs Coma, Josep Serra, Isidor Muntadas, Pere Dalmases, Bartomeu Vidal y Manuel Girona en representación de la Diputación y de las instituciones económicas barcelonesas; Josep Rexach y Joan Vidal de Llobatera en representación de la Diputación gerundense; Josep Antoni Morlins y Ramon de Casanovas, de la ilerdense; y el marqués de Ballet y Joaquim Bartrina, de la tarraconense. 
Los "vales" puestos inicialmente en circulación se cambiaron posteriormente por billetes de más difícil falsificación. La permuta tuvo lugar del 6 al 31 de mayo de 1853. En esta ocasión, el trueque se centralizó en el salón de Sant Jordi del palacio de la Generalitat. Las condiciones de circulación de esta voluminosa masa de papel moneda habían quedado especificadas grosso modo en el Real Decreto de 5 de agosto de 1852, pero fueron matizadas y modificadas en algunos aspectos por una Real Orden de 6 de diciembre de 1852. Esta disposición estableció que "será forzoso el curso y la admisión de los abonarés en todas las transacciones públicas y privadas que se verifiquen en las provincias de Cataluña (...) en la proporción de un diez por ciento del importe total de los pagos...", y precisó que esta normativa sería de obligado cumplimiento "sean cualesquiera las épocas y condiciones de los contratos y la moneda en que se hubiere estipulado el verificarlos...", incluso en la negociación de letras y pagarés girados sobre el Principado, el resto de España o el extranjero y en la de valores bursátiles. Por último, en el curso de 1853 se ordenó que las delegaciones de Hacienda de las cuatro provincias catalanas "recibirán (...) y entregarán en sus pagos un 20 p. \% en calderilla o en abonarés de las cantidades que ingresen o salgan...", lo que comportó el establecimiento, en el Principado, de un régimen especial —al margen de lo que dispuso el decreto de junio de 1852- encaminado, obviamente, a generar confianza en el papel emitido $y$, consecuentemente, a ampliar su aceptación y circulación ${ }^{30}$. De esta manera, Cataluña tuvo en circulación, a partir de 1852, una considerable masa de moneda fiduciaria no convertible al margen de la creada por la banca de emisión. Los "billetes-calderilla" en manos del público representaban, a finales de 1853, un valor nominal de 8.695.615 pesetas (Cuadro 2), mientras que los billetes que el Banco de Barcelona tenía en circulación sólo sumaban 1.242.900 pesetas.

Como es natural, la gran incógnita que conllevaba la operación era si esta singular moneda fiduciaria no convertible a la vista — los "billetes-calderilla" - mantendría la paridad de cambio que tenía asignada con la moneda de oro y de plata. El temor a su posible depreciación obsesionó a los integrantes de la Junta de Moneda incluso antes de que dicho papel fuera puesto en manos del público. Tenían muy presente que su desvalorización podía ocasionar pérdidas considerables a industriales y comerciantes, lo cual no se había producido anteriormente a pesar de que los fabricantes cobraban parte de sus ventas en moneda de cobre catalana, porque "podían colocar la calderilla con facilidad en el pago de jornales, cosa a que por su indivisibilidad e índole no se presta el papel moneda...". Una vez retirada de la circulación la calderilla, tendrían que admitir los billetes, mientras que el pago de jor- 
nales y la compra de materias primas procedentes del resto de España y del extranjero, sobre todo las de algodón en rama, se habría de verificar en efectivo, en este último caso por "la costumbre de ser satisfechas en plata u oro" sin poder ni en uno ni en otro caso colocar los abonarés ${ }^{31}$. Para prevenir dicha eventualidad, a finales de septiembre de 1852, la Junta de Moneda propuso iniciar de inmediato la amortización de los "vales" puestos en manos del público o; en caso contrario, asignar a dicho papel un interés del 3 por 100 mientras se hallase en circulación. Alternativamente se pedía crear un fondo en metálico con objeto de retirar parte de los billetes de la circulación en caso de depreciarse.

Estos temores se confirmaron casi de inmediato. El 26 de octubre de 1852, cuando los "vales" se acababan de distribuir, la Junta de Moneda se hizo eco del "descrédito en que ha empezado a caer el papel moneda emitido con motivo de la recogida (sic) de la calderilla...". Los miembros de la Junta observaron que el "papel moneda que se pone en circulación además de los inconvenientes anejos a los valores de su clase, tiene el especialísimo de no contar con otra garantía que el de una amortización que (...) puede diferirse hasta más allá de veinte años..."32. En consecuencia, orientaron sus esfuerzos a tratar de acelerar el inicio de la amortización y a conseguir que las cuatro Diputaciones del Principado acordaran repartir el coste de la mitad que les correspondía en función de la cuota de contribución industrial y de comercio que tenía asignada cada provincia ${ }^{33}$. La noticia de que existía la intención de acometer la amortización frenó la depreciación del papel: "ha llegado el descuento de los abonarés hasta el 22 por ciento con todos los disgustos y fatales consecuencias de tan considerable depreciación, descuento que ha disminuido hasta el 12 y 10 por ciento..."34. Pero el propósito de afianzar la confianza del público se vio mediatizado por la tardanza en la aprobación de dicho reparto provincial, que no tuvo lugar hasta la promulgación de la Real Orden de 24 de mayo de 1853.

De otro lado, el gobierno estaba empeñado en resarcirse del coste que le había supuesto la calderilla aportada para efectuar el cambio en metálico, y a tal efecto dispuso (por Real Orden de 6 de diciembre de 1852) que se volviera a poner en circulación parte de la calderilla catalana recogida, es decir, las piezas que tuvieran un peso y una acuñación adecuados con las siguientes equivalencias: de 8 maravedís las "sisenes" (piezas de 6 cuartos) y de 4 las "tresenes" (de 3 cuartos). La Junta de Moneda

31 ADB, legajo 183, Actas..., sesión de 24 de septiembre de 1852.

32 ADB, legajo, 183, Actas..., sesiones de 26 y de 30 de octubre de 1852.

33 La Junta propuso (a finales de noviembre de 1852) que dicho reparto se distribuyera del siguiente modo: un 53 por 100 a cargo de la provincia de Barcelona; un 17,88 por 100 de la de Tarragona; un 16,47 por 100 de la de Gerona; y un 12,65 por 100 de la de Lérida. Por otra parte, sugirió que las provincias catalanas dedicasen, en conjunto, 75.000 duros anuales a la mencionada amortización. ADB, legajo 183, Actas..., sesión de 12 de diciembre de 1852. 


\section{CUADRO 2}

VALOR NOMINAL DE LA MONEDA FIDUCIARIA QUE QUEDÓ EN CIRCULACIÓN EN CATALUÑA DESDE FINALES DE 1853 POR EFECTO DE LA RETIRADA DE LA CIRCULACIÓN DE LA CALDERILLA CATALANA (pesetas)

\begin{tabular}{|c|c|}
\hline & $\begin{array}{l}\text { Valor nominal } \\
\text { en circulación }\end{array}$ \\
\hline Billetes* & 8.586 .575 \\
\hline Serie C, número 25.489 de 10 duros & 1.274 .450 \\
\hline Serie D, número 26.499 de 25 duros & 3.312 .375 \\
\hline Serie E, número 15.999 de 50 duros & 3.999 .750 \\
\hline "Vales" en circulación (1-2) & 109.040 \\
\hline 1. Total puesto en circulación de 3 y de 5 duros & 637.640 \\
\hline Serie A, número 15.276 de 3 duros & 229.140 \\
\hline Serie B, número 16.340 de 5 duros & 408.500 \\
\hline 2. Amortizados ${ }^{\star \star}$ & 528.600 \\
\hline Serie A, número 10.895 de 3 duros & 163.425 \\
\hline Serie $B$, número 14.607 de 5 duros & 365.175 \\
\hline Total billetes y "vales" en circulación & 8.695 .615 \\
\hline \multicolumn{2}{|c|}{$\begin{array}{l}\text { (*) El valor nominal de los billetes cambiados por "vales" en mayo de } 1853 \text { de las series C, D y E —de 10, } 25 \text { y } 50 \text { duros, } \\
\text { respectivamente— alcanzó una cifra algo superior a la que la Junta de Moneda — según el recuento contenido en el } \\
\text { acta de } 26 \text { de abril de } 1853 \text { - consideró que existía en circulación. El valor nominal de los "vales" de estas series se } \\
\text { había cifrado en } 8.574 .475 \text { pesetas, mientras que el de los billetes de las mencionadas series que se pusieron en } \\
\text { manos del público a cambio de los "vales" ascendió a } 8.586 .575 \text { pesetas. } \\
\text { (**) Por Real Orden de } 6 \text { de diciembre de } 1852 \text {, el gobierno ordenó la amortización en metálico de los "vales" de } 60 \text { y de } \\
100 \text { reales. La operación se financió con } 260.122,5 \text { pesetas aportadas por el Estado — procedentes del sobrante del } \\
\text { millón de duros de moneda de cobre remitidos para retirar de la circulación la calderilla catalana - y las } 268.477,5 \\
\text { pesetas restantes las aportaron en metálico las diputaciones catalanas. }\end{array}$} \\
\hline
\end{tabular}

Fuentes: ADB, legajo 183, Actas de la Excma. Junta de Moneda de Cataluña.

se opuso taxativamente a ello, temiendo, sin duda, que si se incrementaba la masa monetaria, la precaria situación de los "vales" empeoraría. En este sentido, alegó, en primer lugar, que la masa de calderilla en circulación en Cataluña era suficiente y que si se incrementaba se volverían a plantear los peligros que se había intentado conjurar con la operación de cambio; y, además, que la calderilla catalana manifiestamente falsa que no se había presentado al cambio reaparecería en caso de volver a 
circular la expresada moneda de cobre y, consiguientemente, se reavivaría la falsificación. En suma, los miembros de la Junta opinaban que era indispensable "que desaparezca del todo la poca moneda de cobre provincial que hoy circula a fin de que se borre, si posible es, hasta la memor(i)a de su existencia y antiguo valor representativo..." 35 . Se mostraron proclives, en cambio, a aceptar la posibilidad de que el gobierno fundiera la masa de calderilla catalana que tenía en su poder; acuñara con ella 4,5 millones de pesetas de calderilla española; y dedicara este dinero a amortizar la mitad de los "vales" que se había convenido financiar a cargo de los presupuestos del Estado. En contrapartida, sugirieron que las Diputaciones catalanas estaban dispuestas a amortizar, en el plazo de nueve años, la mitad que les correspondía y a indemnizar al gobierno por haber anticipado su compromiso haciéndose cargo de los gastos de reacuñación o abonando a Hacienda un interés del 5 por 100 de la suma avanzada por el Estado. Esta expectativa se desvaneció definitivamente a raíz de que el gobierno dispuso (por Real Orden de 19 de agosto de 1853) el traslado de la calderilla catalana depositada en las tesorerías de Hacienda del Principado para servir de materia prima a las acuñaciones estatales.

En mayo de 1853 se efectuó, según se había previsto, el cambio de los "vales" por "billetes-calderilla", pero nada se decidió respecto a su amortización. Pasaron los meses y la Junta de Moneda de Cataluña se sumergió en la más absoluta inactividad, hasta el punto de que apenas se reunió en el transcurso de 1854. En el año siguiente, su primera reunión no tuvo lugar hasta el mes de junio. En la misma, Manuel Girona advirtió que "no podía prescindirse de acudir en ausilio del papel calderilla y de evitar de todos modos su depreciación...", y todos los asistentes, después de convenir que ello perturbaba las transacciones mercantiles y encarecía los artículos, decidieron volver a reclamar que se tomara alguna providencia acerca de su amortización ${ }^{36}$. Esta demanda no tuvo ningún efecto. En marzo de 1856, la Diputación de Barcelona trató de afrontar esta cuestión y propuso al gobierno el establecimiento de un nuevo arbitrio (de un real por cuartera) sobre las importaciones de trigo que el Principado efectuaba del resto de España, con objeto de destinar el producto obtenido a cumplir el compromiso de amortización adquirido por las diputaciones catalanas. Por Real Orden de 17 de junio de 1856, el ministro de Hacienda autorizó el cobro de esta carga, pero esta disposición fue recurrida por el gobernador civil de Barcelona. El jefe político adujo, alarmado, que este impuesto tendría repercusiones alcistas sobre el precio del pan, cuando este alimento básico experimentaba, desde hacía años, una acusada alza derivada del incremento de los precios del trigo — eran los años de la Guerra de Crimen—37 y evidenció 
que debido a "las circunstancias difíciles que atravesaba esta capital, era materialmente imposible, sin provocar un conflicto, recargar este artículo con un real cuando su precio es tan elevado...". Esto, a su entender, había de prevalecer en la consideración de toda persona sensata..."38. Pese a tal impugnación, los miembros de la Junta de Moneda no renunciaron a que se cumpliera dicha disposición porque, según manifestó M. Girona, "abandonar la cuestión de la amortización (...) era hundir absolutamente el papel circulante..." ${ }^{\prime 39}$. En el transcurso de los meses siguientes, la tendencia alcista de los cereales culminó en una profunda crisis de subsistencias y quedó claro que era del todo inconveniente aumentar la presión tributaria sobre el trigo y la harina. En estas circunstancias, la Junta de Moneda de Cataluña se desintegró, al parecer, definitivamente - en el libro de actas no consta que se celebrara ninguna otra reunión-, sin haber conseguido encauzar una de las funciones fundamentales que tenía atribuidas: establecer los plazos y condiciones en los que el Estado y las Diputaciones catalanas habían de proceder a la amortización de los "billetes-calderilla".

\subsection{El dinero creado por las sociedades de crédito y las cajas de descuento}

Como vimos más arriba, las leyes restrictivas de 1849 y 1851, y el impacto de la crisis de 1848 determinaron una notable reducción de los billetes que el Banco de Barcelona mantenía en circulación. Se pasó de los 7,3 millones de pesetas acreditados a finales de 1847 a poco más de 1,3 millones en diciembre de 1852 (Gráfico 1). Los efectos de esa reducción empezaron a hacerse evidentes en cuanto se superó el impacto depresivo del pánico de 1848. El Banco registró un aumento extraordinario de las cuentas corrientes y observó como los talones girados contra ellas eran utilizados de forma masiva como medios de pago. Los directivos de la entidad atribuyeron el hecho a la falta de billetes ${ }^{40}$. La escasez llegó a tal punto que el Banco solicitó al gobierno poder emitir billetes con una cobertura del 100 por 100. O sea, manteniendo en caja la totalidad de su importe en metálico. Sin duda, se trataba de una reacción de los directivos del banco ante el malestar existente en la ciudad por la escasez de billetes ${ }^{41}$. Simultáneamente, empezaron a circular por la plaza otros activos

\footnotetext{
38 ADB, legajo 183, Actas..., sesión de 29 de junio de 1856.

39 ADB, legajo 183, Actas..., sesión de 29 de junio de 1856.

40 Ya en 1850 la dirección se lamentaba de los costes que implicaba el "multiplicarse excesivamente las libranzas ó talones de sus tenedores (de las cuentas corrientes) por efecto natural de la escasez de billetes...". ANC, BB, Actas de la Junta de Gobierno, 9 septiembre 1850.

41 ANC, BB, Actas de la Junta de Gobierno, 10 de enero de 1855.
} 
monetarios emitidos por particulares, especialmente cambistas. El propio banco lo denunció en 1855 y lo ratificó una inspección general realizada posteriormente ${ }^{42}$.

Esta situación de escasez de medios de pago, que no era exclusiva de la capital catalana, explica que en ese mismo año diversos diputados presentasen ante las cortes progresistas un proyecto de ley que proponía una libertad casi total de emisión. Las únicas exigencias eran que las acciones de los bancos emisores fueran nominativas y que se mantuviera un tercio del monto emitido en metálico ${ }^{43}$. El gobierno, presionado por el Banco de San Fernando, se vio obligado a intervenir presentando su propio proyecto, mucho más moderado ${ }^{44}$. Las vicisitudes de la discusión parlamentaria subsiguiente, bien conocidas ${ }^{45}$, dieron lugar a la aprobación de las leyes de bancos de emisión y de sociedades de crédito de 28 de enero de 1856.

En Barcelona, la primera iniciativa para crear nuevas entidades de crédito fue anterior a la aparición de la ley. En mayo de 1855 el gobierno autorizó la entrada en funcionamiento de la Caja Barcelonesa de Giros, Descuentos, Préstamos y Cuentas Corrientes, cuyos primeros estatutos se habían presentado en diciembre de 1853 . Unos meses más tarde, en noviembre de 1856, se aprobaba la constitución de la Caja Catalana Mercantil e Industrial. Ambas entidades se acogieron a la ley general de sociedades anónimas y no a las específicamente bancarias y, por lo tanto, dependían del Ministerio de Fomento. Su actividad fue fundamentalmente de banca comercial. Prestaban a corto plazo mediante el descuento de efectos comerciales y en cuenta corriente con garantía de materias primas, títulos de deuda, acciones y obligaciones ${ }^{46}$. Captaban recursos mediante cuentas corrientes remuneradas al 1 por 100 sobre el saldo medio la Catalana y al 2 por 100 sobre el saldo mínimo la Barcelonesa. Sin embargo, una parte importante de su pasivo procedía de la emisión de órdenes de pago y de la circulación de talones no presentados al cobro. Unas y otros eran convertibles a la vista y circulaban como dinero entre el público mediante endoso por simple firma.

42 El Comisario Regio del banco, en octubre de 1855, se refería a la existencia de "órdenes al portador" o "depósitos simulados"en su respuesta a una consulta del Gobierno en relación al proyecto de ley de bancos (Archivo del Congreso de los Diputados, leg. 100, n. 36, carpeta 1). Debemos esta referencia a la amabilidad de Yolanda Blasco. En 1859 un informante cualificado afirmaba que antes de la entrada en vigor de las leyes de 1856 muchos comerciantes aceptaban como moneda unos abonarés emitidos por "simples cambiantes de moneda sin la menor responsabilidad y sin otro moviliario y ajuar que unas mesas de pino colocadas en las plazas públicas. Archivo Histórico Nacional (AHN, en adelante), Hacienda, legajo 429/1, Memoria redactada por D. José Fariñas relativa a la visita girada a las sociedades de crédito de Barcelona (12 de julio de 1859).

Véase el dictamen de la comisión parlamentaria correspondiente, emitido el 15 de junio de 1855. Gaceta de Madrid, 22/6/1855.

44 Santillán (1982 (1865)), vol. II, p. 63.

45 Tortella (1973), pp. 51-63.

46 Véanse las memorias de estas sociedades; por ejemplo, de la Junta general de la Caja Catalana celebrada el 7 de febrero de 1858 (Caja Catalana Mercantil e Industrial, 1858) y de la Junta general de la Caja Barcelonesa celebrada el 24 de enero de 1858 (Caja Barcelonesa de Giros, Descuentos, Préstamos y Cuentas Corrientes, 1858). 
Inmediatamente después de la aprobación de la ley de sociedades de crédito surgieron en la ciudad diversas iniciativas dirigidas a crear entidades de este tipo. En primera instancia llegaron a materializarse tres de estas iniciativas: la Sociedad Catalana General de Crédito, el Crédito Mobiliario Barcelonés y la Unión Comercial. Estas entidades tenían como finalidad la promoción y financiación de infraestructuras y fueron muy activas en la financiación de la red ferroviaria catalana y en otras iniciativas, como la reforma del puerto de la ciudad o la puesta en marcha de explotaciones forestales. En este caso, la financiación se obtuvo por la vía de las cuentas corrientes, por la emisión de obligaciones a muy corto plazo y, en menor medida, también por la emisión de órdenes de pago y de talones registrados. La posibilidad de que las obligaciones con vencimiento a corto plazo (el mínimo eran 30 días) acabaran siendo utilizadas como billetes ya fue señalada en la discusión parlamentaria de la ley, pero el artículo fue aprobado sin dificultad ${ }^{47}$. De las tres sociedades creadas, la Unión Comercial tuvo una vida corta, liquidando en 1859. En años posteriores se crearon tres sociedades más, el Crédito Mercantil, Crédito y Fomento, y El Comercio. No parece que ninguna de estas tres entidades emitiera activos monetarios. De hecho, tanto el Crédito Mercantil como la sociedad El Comercio llegaron a sendos acuerdos con el Banco de Barcelona para utilizar sus billetes en sus transacciones. El Banco les cedía billetes a cambio de redescontar su cartera y de algunas garantías adicionales, y las sociedades de crédito pagaban a sus clientes con ellos ${ }^{48}$.

Como es natural, la proliferación de activos que actuaban como billetes suscitó la más enérgica repulsa por parte del Banco de Barcelona, poseedor legal del derecho de emisión. Remitió al gobierno repetidas solicitudes para que se impidiese la circulación de ese papel, pero no obtuvo satisfacción. Durante la crisis de 1857, el gobierno - temeroso de que se produjera un pánico financiero general— mandó realizar un amplio estudio sobre la situación financiera de la ciudad y acabó dictando una real orden que imponía la retirada del papel ilegal en un plazo de tres meses. Poco después, sin embargo, una nueva real orden excluía de la prohibición los talones registrados, las órdenes de pago y las obligaciones, con lo que la primera disposición quedó vacía de contenido ${ }^{49}$. La pugna siguió en los años siguientes, pero finalmente fue el propio Banco de Barcelona el que tuvo que plegar velas. En diciembre de 1862, ante la presión de sus propios clientes, el Banco acordó aceptar en sus cajas el papel de todas las sociedades y se estableció de común acuerdo un sistema de compensación. En esos momentos ya no eran tan sólo las entidades citadas las que emitían activos monetarios, sino que lo hacían también diversas casas de banca

\footnotetext{
$47 \quad$ Tortella (1973), pp. 61-62.

48 ANC, BB, Actas de la Junta de Gobierno, 1/2/1864 (para el Crédito Mercantil); y 1/5/1865 (para El Comercio).

49 Reales Órdenes de 26 de julio y de 28 de setiembre de 1857.
} 


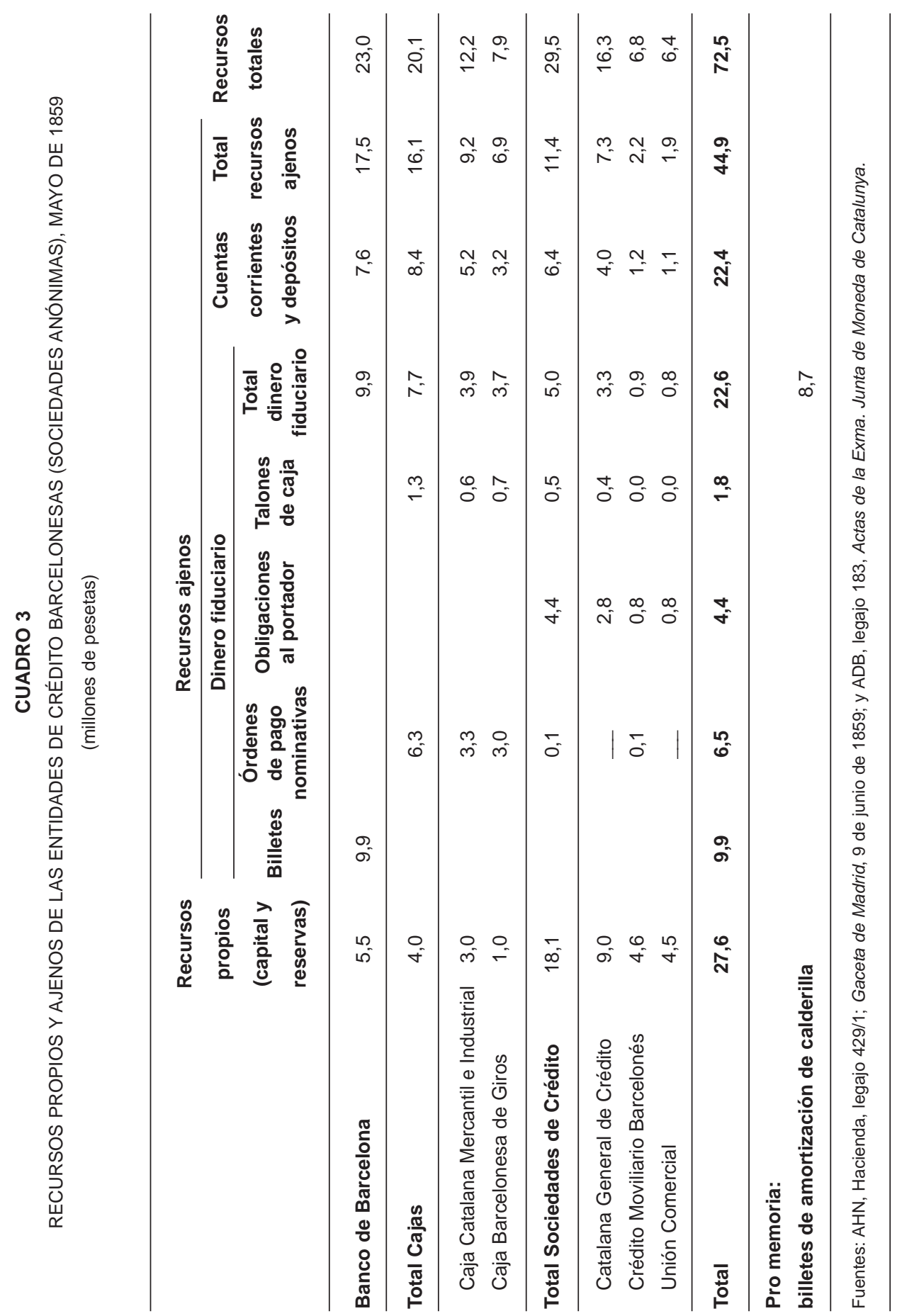


comanditarias, como la Caja Mutua, la Caja Vilumara, la Caja Auxiliar del Comercio y el Fomento del Crédito ${ }^{50}$.

La magnitud de las emisiones de las entidades financieras barcelonesas fue sin duda muy importante. Las cifras correspondientes a 1859 para las sociedades anónimas se han sistematizado en el Cuadro 3. Como se puede observar, la principal entidad de crédito barcelonesa de la época, por los recursos disponibles, era el Banco de Barcelona, pero representaba tan sólo poco más de un tercio del total. En lo referido al dinero fiduciario puesto en circulación por las diversas entidades, los billetes del banco suponían menos de la mitad, un 44 por 100. Los principales emisores, tras el banco, eran las cajas de giro y banca y la Catalana General de Crédito.

Esta situación real de free banking tolerado aunque dudosamente legal, se mantuvo hasta el estallido de la crisis de $1866^{51}$. En febrero de ese año, la conjunción de la crisis fiscal del Estado con la crisis ferroviaria y bursátil propició la generación de un pánico que se concretó en demandas masivas de reembolso por parte de los tenedores de billetes y otros activos monetarios. Hubo suspensiones de pagos e imposición de restricciones al reembolso por parte de las autoridades. La crisis se saldó con la retirada del papel fiduciario emitido por las entidades no autorizadas para ello y su sustitución por billetes del banco. La mayoría de las entidades afectadas tuvieron que liquidar y el Banco pudo recobrar su posición monopolista ${ }^{52}$. Aunque las pérdidas por parte de los tenedores de activos monetarios y los titulares de cuentas corrientes no fueron muy importantes, la ciudad quedó afectada durante los años siguientes por una fuerte atonía financiera.

\section{La plasticidad de la oferta monetaria en un sistema monetario de transición}

Las cifras hasta ahora manejadas no permiten un acercamiento, ni que sea aproximado, a la estructura de la oferta monetaria existente en Cataluña en la segunda mitad de la década de 1850. Si aceptamos la estimación realizada por Gabriel Tortella

$50 \quad \mathrm{ANC}, \mathrm{BB}$, Actas de la Junta de Gobierno, 29 de diciembre de 1862.

51 La competencia en la emisión de billetes de banco ha sido objeto de gran atención, tanto por parte de economistas teóricos como de historiadores económicos. En el ámbito de la historia bancaria los trabajos clásicos son los de Rockoff (1975) y White (1984), para los Estados Unidos y Gran Bretaña, respectivamente. Una recopilación de más de cincuenta artículos sobre el tema en White (1992).

52 Sobre la crisis, los primeros estudios modernos en Sánchez-Albornoz (1963) y (1977), cap. 7; Tortella (1973), pp. 279 y ss.; Pascual (1990), pp. 261-292; y Tafunell (1991), pp. 379-385. Una revisión reciente con nuevas aportaciones en Navas y Sudrià (en prensa). 
de la moneda de oro y plata en circulación en España, que se sitúa para 1859 en 863 millones de pesetas ${ }^{53}$, y atribuimos a Cataluña entre un 15 y un 20 por 100 de esa cifra $^{54}$, estaríamos hablando de una masa monetaria con valor intrínseco circulando por el Principado de entre 130 y 170 millones de pesetas. Junto a ella tendríamos unos 4 millones de calderilla, los casi 23 millones de pesetas de activos monetarios convertibles a la vista y los 8,7 millones adicionales de los billetes de amortización de calderilla. Por consiguiente, la moneda fiduciaria en papel representaría entre un 15 y un 20 por 100 de la oferta monetaria total.

Las distintas clases de moneda fiduciaria en circulación fueron, sin duda, ampliamente utilizadas por los comerciantes e industriales barceloneses a partir de 1855. Las cartas de pago y los contratos de compra-venta contenidos en los protocolos notariales avalan esta realidad, pues eran contadas las transacciones en las que no intervenían. La estructura de las disponibilidades líquidas en caja de las sociedades de crédito y de las cajas de descuento barcelonesas a finales de 1858 constituye una evidencia cuantitativa adicional de la magnitud alcanzada por la circulación de estos medios de pago (Cuadro 4).

Como es bien sabido, en un sistema monetario con papel moneda plenamente convertible, el volumen del mismo que puede ponerse en circulación tiene límites. El proceso de crecimiento de la oferta monetaria sólo puede producirse por la vía de un aumento de la oferta crediticia generada por el conjunto del sistema bancario y, por lo tanto, se verá afectado por cualquier retroceso coyuntural de la renta que implique una regresión más o menos intensa de la demanda de crédito. Por otro lado, un déficit de la balanza básica exterior que ocasione salidas netas de moneda con valor intrínseco producirá cambios en las necesidades de liquidez de los agentes económicos. Para efectuar sus pagos al exterior estos agentes precisarán moneda de oro o plata y, seguramente, tendrán que convertir parte de sus tenencias de moneda fiduciaria o variar las proporciones entre una y otra. Lo que no prescribe la teoría, sin embargo, es cómo afectarán estos ajustes a los diferentes tipos de moneda fiduciaria convertible o, eventualmente, a la moneda con valor intrínseco. La situación es diferente respecto a la moneda fiduciaria de curso forzoso, como los billetes-calderilla. En este caso es de esperar que se produzca una desvalorización de este tipo de moneda respecto a la de valor intrínseco, siempre, naturalmente, que sea esta última la referencia efectiva de valor.

$53 \quad$ Carreras y Tafunell (2005), p. 678.

54 Según Álvarez Llano (1986), el PIB catalán representaba en 1860 un 13,3 por 100 del PIB español. Parece indudable que el nivel de monetización de la economía catalana era, en esta época, superior al de la media española. En primer lugar, porque existía en la región un grado más elevado de comercialización del producto agrario, debido a que los cultivos especializados, como la vid y el olivo, ocupaban una superficie relativamente muy superior (Garrabou y Pujol, 1987, pp. 35-83). En segundo lugar, debido a que la aportación del producto industrial al PIB era sensiblemente superior al de la media española (Nadal, 1992, p. 153). 


\section{CUADRO 4}

ESTRUCTURA DE LAS DISPONIBILIDADES LÍQUIDAS EN CAJA DE LAS SOCIEDADES DE CRÉDITO Y DE LAS CAJAS DE DESCUENTO BARCELONESAS, 31 de Diciembre de 1858*

\begin{tabular}{|c|c|c|}
\hline & $\begin{array}{l}\text { Millones } \\
\text { de pesetas }\end{array}$ & Porcentajes \\
\hline Metálico en moneda de oro y de plata & 6,3 & 51,4 \\
\hline Billetes-calderilla & 1,5 & 12,6 \\
\hline Billetes del Banco de Barcelona** & 0,9 & 7,2 \\
\hline Obligaciones, talones, órdenes de pago, etc., de diversas sociedades & 3,5 & 28,8 \\
\hline Total & 12,2 & 100,0 \\
\hline \multicolumn{3}{|c|}{$\begin{array}{l}\text { (*) El valor nominal de los billetes del Banco de Barcelona que estas entidades financieras tenían en caja era algo supe- } \\
\text { rior a la suma consignada aquí, porque en el balance de la Caja Catalana los billetes indicados se contabilizaron de } \\
\text { manera agregada con los otros activos monetarios puestos en circulación por los restantes establecimientos banca- } \\
\text { rios barceloneses. } \\
\text { (**) Total agregado de las existencias líquidas en caja de las siguientes entidades financieras: Caja Catalana, Caja Bar- } \\
\text { celonesa, Catalana General de Crédito, Crédito Mobiliario Barcelonés y Unión Comercial. En ningún caso se han } \\
\text { contabilizado los billetes, talones, órdenes de pago y obligaciones que tenían en caja los propios establecimientos } \\
\text { emisores de dichos medios de cambio. }\end{array}$} \\
\hline
\end{tabular}

Fuentes: AHN, Hacienda, legajo 429/1.

La crisis que se produjo en toda España en 1856-1857 nos servirá de ejemplo para observar los efectos de una contracción de la actividad en el complejo mercado monetario catalán. Como es sabido, la caída de la producción de cereales del verano de 1856 conjuntamente con la exportaciones previas y la especulación condujeron a un fuerte incremento de los precios del trigo ${ }^{55}$. Este hecho incidió negativamente sobre el crecimiento de la producción industrial catalana durante el bienio de 1857$1858^{56}$. Paralelamente, el comercio con América, que tenía a los vinos como producto básico de exportación, acusó una acentuada regresión ${ }^{57}$, lo cual contribuyó a intensificar la depresión en la economía real. Todo ello, unido a las elevadas importaciones de cereales extranjeros, autorizadas con exención arancelaria a fin de atajar la escasez, determinó que el sector exterior catalán saldara con crecidos déficit según pone de manifiesto el cambio, en Barcelona, de las letras giradas sobre Londres y

\footnotetext{
55 Sánchez-Albornoz (1977), pp. 27-67.

56 Carreras (1990), p. 56.

57 Valls (2003), pp. 402-403.
} 
París ${ }^{58}$. Según todos los indicios, dicha coyuntura implicó, de un lado, que la demanda monetaria agregada pasara de la expansión al estancamiento (o tal vez, incluso, a la regresión) y, del otro, que los agentes económicos se vieran abocados a una situación en la que disponían de un exceso de moneda fiduciaria y de una cantidad insuficiente de moneda con valor intrínseco para atender a sus obligaciones de pago fuera de la plaza.

El exceso de moneda fiduciaria y la relativa escasez de metálico determinaron una creciente presión del público sobre los establecimientos bancarios en demanda de conversión de los billetes, órdenes de pago, talones, etc. Paralelamente, la iliquidez ocasionada por las tensiones depresivas de la economía determinó una progresiva reducción de los saldos en cuentas corrientes y depósitos bancarios en los primeros meses de 1859. En esta coyuntura, el banco, las cajas y las sociedades de crédito experimentaron una severa reducción del metálico en caja destinado a asegurar la convertibilidad del papel. La caída del encaje metálico forzó a los dirigentes de las entidades bancarias a reducir drásticamente la oferta crediticia a fin de disponer de los recursos indispensables para hacer frente al alud de demandas de conversión, lo cual determinó que se produjera una contracción, casi traumática, de la oferta monetaria.

Las cifras muestran que el ajuste monetario provocado por dichas causas entre abril y agosto de 1859 conllevó una reducción de la oferta de moneda fiduciaria convertible del 14 por 100. Si añadimos a ello la disminución ya citada de los saldos en cuentas corrientes y depósitos, veremos que la contracción de la oferta monetaria neta generada por el conjunto de la banca barcelonesa fue del orden del 24,5 por 100 (Cuadro 5).

Vale la pena observar que el impacto de la reducción fue muy diferente según el tipo de activo. Destaca, en primer lugar, que los billetes de banco fueron los que menos sufrieron las exigencias de conversión. Se detecta también que las órdenes nominativas (emitidas por las cajas) resultaron menos afectadas que las obligaciones a corto plazo, propias de las sociedades de crédito. Finalmente, el activo más perjudicado por la reducción fueron los talones registrados, quizá porque se pensaba que su circulación más allá de la fecha consignada conllevaba un mayor riesgo legal. No debe pasar desapercibido que el incremento de las existencias en caja se concentró en la moneda metálica, mientras que se redujeron las tenencias de activos monetarios emitidos por otras entidades y de billetes de calderilla. De lo dicho parece deducirse que, a la hora de recomponer sus carteras de activos monetarios, los comerciantes e industriales barceloneses apreciaban de forma distinta activos monetarios que, en principio, tenían la misma función. Sus preferencias pueden deberse a razones de 


\section{CUADRO 5}

CONTRACCIÓN DE LA OFERTA MONETARIA NETA GENERADA POR LA BANCA BARCELONESA

ENTRE ABRIL Y AGOSTO DE 1859

(millones de pesetas)*

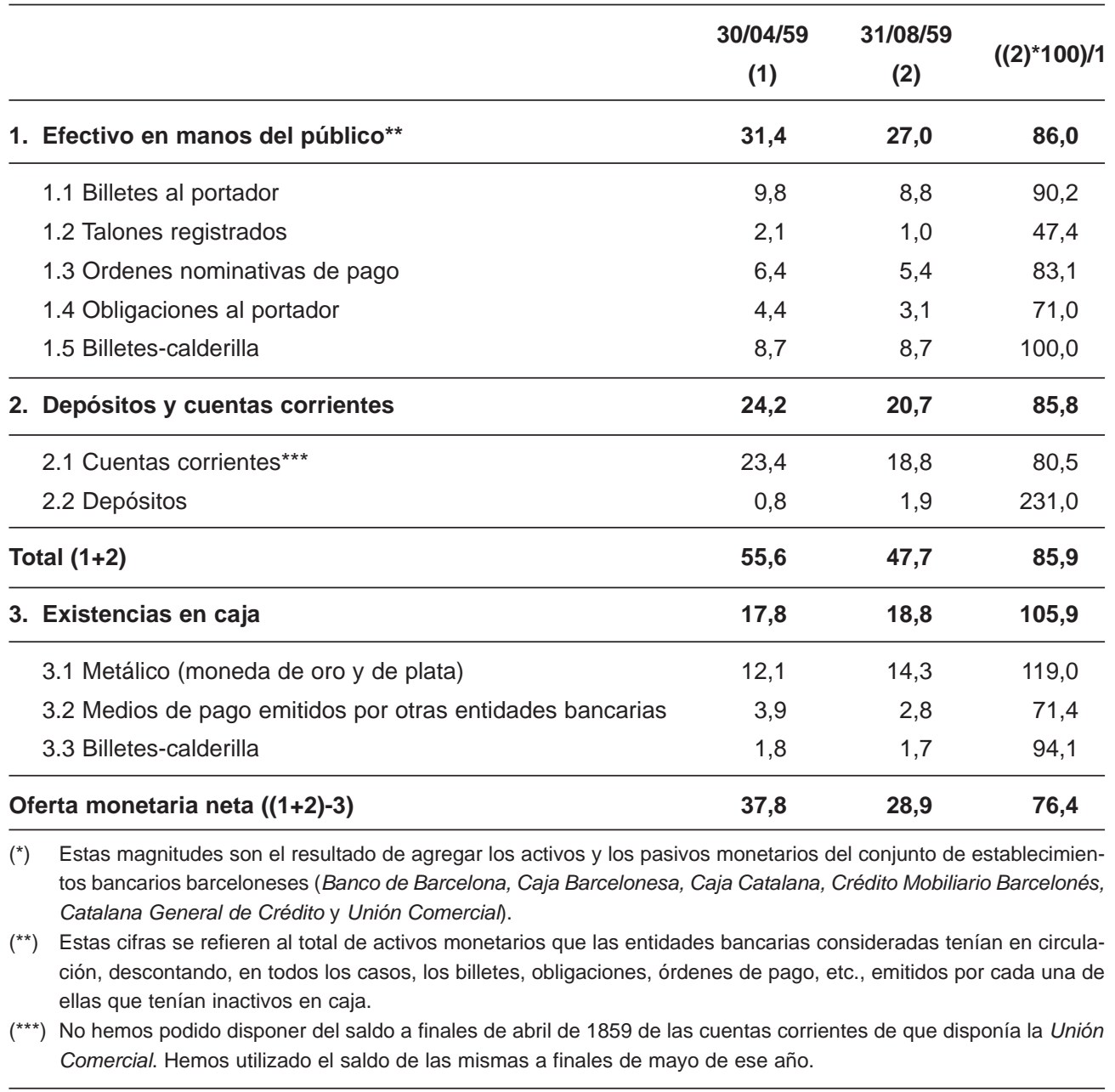

Fuentes: AHN, Hacienda, legajo 429/1.

índole legal o bien a una mayor confianza en unas que en otras entidades. En todo caso conviene tener en cuenta que, pese a la agudeza de la contracción, ninguno de los activos en circulación fue completamente rechazado por el mercado. 


\section{GRÁFICO 2}

COTIZACIÓN DE LOS BILLETES-CALERILLA, 1855-1867 (en porcentaje)

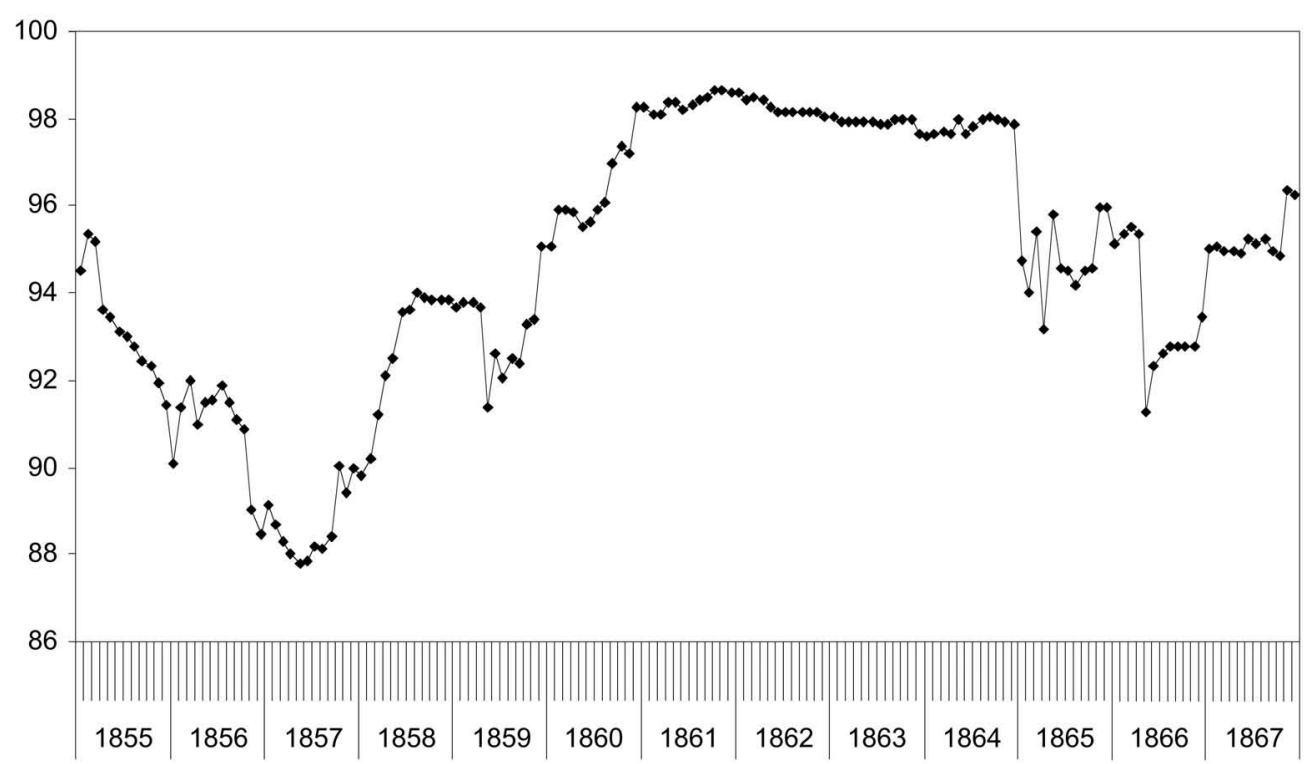

Fuentes: Apéndice.

Veamos ahora lo ocurrido con los billetes-calderilla. Recordemos que se trataba de un activo monetario no convertible a la vista y con curso forzoso limitado al 10 por 100 de las transacciones. En este caso, por lo tanto, la contracción ante la caída de la demanda monetaria no podía tener lugar por la vía de la reducción del número de billetes en circulación: solo podía producirse por la vía de la depreciación. El Gráfico 2 muestra la cotización que alcanzaron los billetes calderilla entre 1855 y 1867.

Como se observa, estos billetes se cotizaron con un quebranto de poca consideración, inferior al 5 por 100, respecto a su valor nominal hasta comienzos de 1855 . A raíz de la crisis de 1857, sin embargo, experimentaron una acusada depreciación, que alcanzó un 12 por 100 a mediados de dicho año. La cotización se recuperó en los meses posteriores, pero esta tendencia quedó interrumpida a mediados de 1859, durante los mismos meses para los que detectamos la reducción de los activos monetarios convertibles en circulación. La situación volvió a la normalidad - un quebranto situado en torno al 2 por 100 - en el transcurso de 1860. A principios de 1865, al iniciarse un nuevo ciclo de contracción financiera, la cotización volvió a descender para alcanzar un nuevo mínimo durante el paroxismo de la crisis de 1866 . Este 
segundo episodio de depreciación hubiera resultado, sin duda, mucho más agudo de no haberse producido, entre 1864 y 1868, la amortización de casi un 40 por 100 de los billetes en circulación ${ }^{59}$.

Vista la evolución de los diversos activos monetarios, resulta pertinente que entremos a valorar el efecto que pudieron tener esas fluctuaciones sobre los precios. Sabemos bien que, a medio plazo, en una economía abierta bajo un sistema de moneda convertible, toda desviación del nivel de precios respecto al exterior acaba ajustándose mediante el déficit o el superávit de la balanza externa, con los consiguientes efectos correctivos sobre la cantidad de dinero en circulación. Sin embargo, es evidente que este tipo de ajuste no es inmediato y pueden darse desviaciones significativas debidas a la propia inercia de los mercados o a la incidencia de los componentes no comerciales de la balanza de pagos.

Comprobar de forma consistente el efecto de las fluctuaciones monetarias sobre los precios exigiría un ejercicio sistemático de carácter comparativo que queda fuera de los objetivos de este trabajo. Sin embargo, la observación de la evolución de los precios en Barcelona durante estos años puede ayudarnos a proponer algunas hipótesis. La serie de referencia es la elaborada por Jordi Maluquer para los precios al consumo (Gráfico 3). La serie muestra una cierta tendencia al alza en estos años, pero que no parece responder a un posible impacto de un incremento de la oferta monetaria, sino a cambios en la oferta de productos básicos. Por ejemplo, el incremento experimentado por los mismos entre 1853 y 1856 fue efecto, en gran medida, del aumento de los precios del trigo, puesto que en la formación del índice de precios al consumo, el del pan y el de la pasta tienen un peso considerable ${ }^{60}$. En cualquier caso, entre 1855 y 1859, la masa de moneda fiduciaria en circulación en Cataluña pasó de 10,5 a 31,7 millones de pesetas y el total de dinero en manos del público, incluyendo la moneda metálica, de 120 a 165 millones de pesetas, un incremento del 35 por $100^{61}$. Entre esos mismos años, los precios tendieron a caer. A partir de 1864 se detecta una caída de los precios, cuando la reducción de la oferta monetaria vinculada a la crisis financiera no se produjo hasta mediados de 1866.

59 La Junta de Carreteras de Cataluña —legalmente obligada - invirtió, durante este quinquenio, nada menos que 3.625.000 pesetas en la amortización de estos billetes; y por efecto de ello, el volumen en circulación quedó reducido a poco más de 5.000 .000 de pesetas (Pascual, 2007, pp. 202-203). Sin embargo, su total amortización no se llevó a cabo hasta 1883 (Fernández y Anes, 1970, p. 160).

El coste de la alimentación se pondera, en esta época, en un 69,4 por 100 del gasto de las familias; y el del pan y el de la pasta en un 24,2 por 100 del mismo (Maluquer, 2006, pp. 349 y 358). Sobre las causas determinantes del incremento de los precios de los cereales y de su magnitud durante dicho período, véase el estudio clásico de Sánchez-Albornoz (1977), pp. 27-67.

61 Cálculo sobre la base de las cifras de moneda metálica en circulación de Tortella (Carreras y Tafunell, 2005, p. 678) atribuyendo a Cataluña un 15 por 100 del total español. Si asumiéramos una proporción del 20 por 100, el incremento sería de 160 a 205 millones de pesetas, un 25 por 100. 


\section{GRÁFICO 3}

ÍNDICE DE PRECIOS AL CONSUMO EN BARCELONA, 1845-1867 (1913=100)

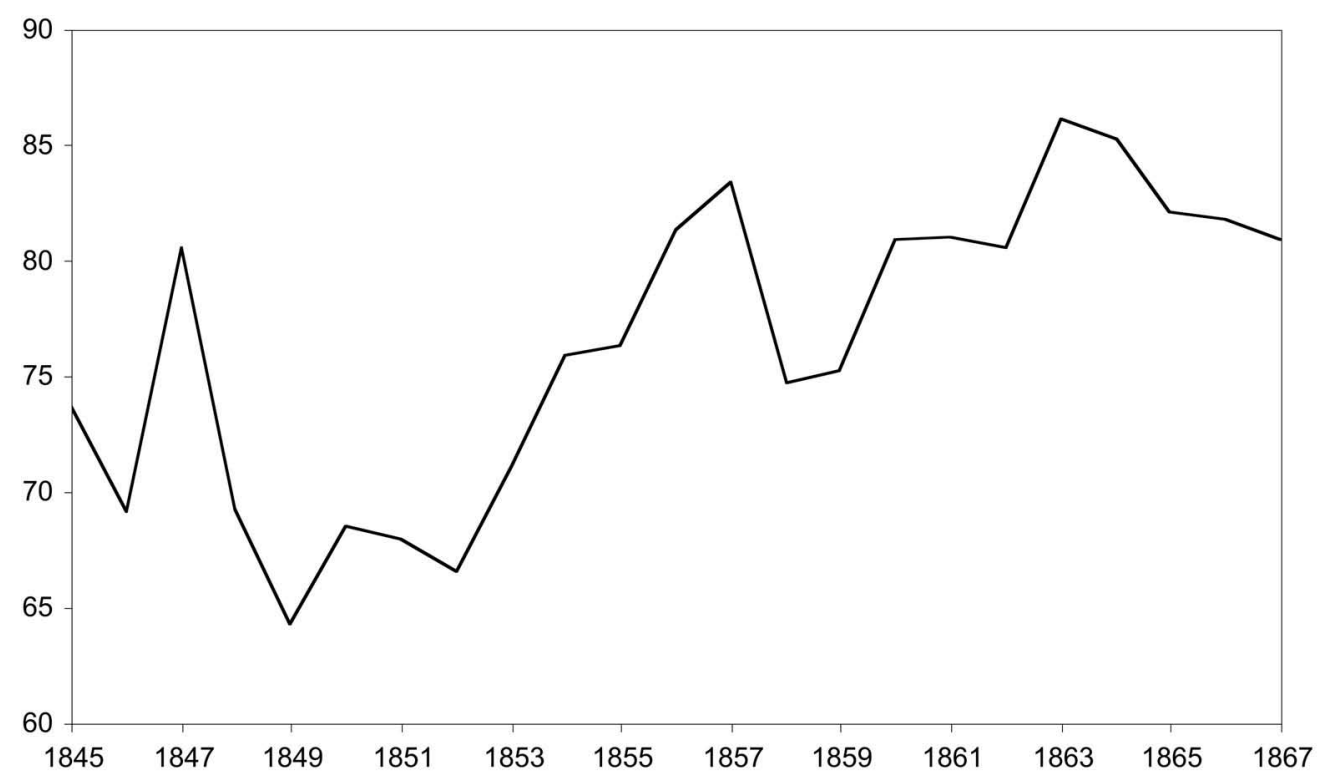

Fuentes: Maluquer (2006)

\section{Conclusiones}

La pretensión de este artículo era estudiar la primera fase de la instauración de un sistema monetario moderno en una región que experimentaba simultáneamente un incipiente proceso de industrialización. Como hemos visto, el sistema monetario barcelonés de mediados del siglo XIX presentaba algunas características peculiares que lo convierten en un interesante objeto de estudio. Sin duda, el aspecto más destacado de ese sistema fue la convivencia de activos monetarios de diverso tipo: billetes convertibles emitidos por el banco legalmente autorizado para ello; billetes convertibles emitidos por otras entidades al margen de la legalidad pero admitidos de facto por las autoridades y por el mercado; y billetes no convertibles a la vista emitidos por un organismo público y de circulación forzosa.

El estudio detallado de lo ocurrido durante la contracción productiva y financiera derivada de la crisis de subsistencias de 1856-1857 nos ha permitido observar que el ajuste a la reducción de la demanda monetaria interna se producía, por un 
lado, por la vía de la disminución de la moneda fiduciaria convertible — presentada a conversión por parte de sus tenedores-y, por otro, por la de la depreciación de la moneda no convertible. El comportamiento del mercado ante los diversos activos convertibles no era homogéneo y obliga a pensar que los tenedores de esos activos los valoraban de forma diferente, aunque su función fuese la misma.

En lo referido a la relación entre la evolución de los precios y la de la oferta monetaria, ya hemos indicado que una correcta evaluación de la interacción entre unas macromagnitudes y otras exigiría un ejercicio que queda fuera de las pretensiones de este trabajo. Sin embargo, consideramos que puede afirmarse que, durante esta etapa de desarrollo financiero y de pluralidad de emisión, el impacto del aumento de la oferta monetaria sobre los precios fue mínimo. La hipótesis más creíble tendría dos vertientes. Por lo que se refiere al sustancial aumento general de la oferta monetaria debida al desarrollo bancario, la idea sería que la mejora y ampliación de los medios de pago generó por sí misma un incremento del producto que explicaría el limitado efecto sobre los precios. Se trata de una propuesta similar a la realizada por Rousseau al dilucidar la vieja paradoja entre una oferta monetaria expansiva y unos precios estables en la Pennsilvania colonial ${ }^{62}$. Al mismo tiempo, las fluctuaciones coyunturales de la actividad habrían tendido a ajustarse mediante una notable plasticidad de la oferta de moneda fiduciaria, en unos casos mediante su reducción y en otros a través de su desvalorización.

En cualquier caso, parece claro que el desarrollo financiero que acaeció en estos años en Cataluña, pese a su carácter notoriamente anárquico, contribuyó decisivamente al incipiente proceso de industrialización.

\section{Bibliografía}

ÁLVAREZ LLANO, Roberto (1986): “Evolución de la estructura económica regional de España en la historia: una aproximación”, Situación, 1, pp. 5-61.

ANES, Rafael (1974): “El Banco de España (1874-1914). Un banco nacional”, en SCHWARTZ, Pedro (ed.), La banca española de la Restauración. I. Política y finanzas, Madrid, Banco de España, pp. 107-215.

BLASCO, Yolanda (2001): “Los protagonistas de la fundación del Banco de Barcelona", Estudis Històrics i Documents dels Arxius de Protocols, XIX, pp. 279-312.

BLASCO, Yolanda, y SUDRIÀ, Carles (en prensa): El Banco de Barcelona (1844-1874). Historia de un banco de emisión.

62 Rousseau (2007). 
BECK, Thorsten; LEVINE, Ross, y LOAYZA, Norman (2000): “Finance and sources of growth", Journal of Financial Economics, 58, pp. 261-300.

BORDO, Michael D., y ROUSSEAU, Peter L. (2006): "Legal-Political Factors and the Historical Evolution of the Finance-Growth Link", European Review of Economic History 10 (3), pp. 421-444.

CABANA, Francesc (1978): Història del Banc de Barcelona (1844-1920), Barcelona, Edicions 62.

CAJA BARCELONESA DE GIROS, DESCUENTOS, PRÉSTAMOS Y CUENTAS CORRIENTES (1858): Memoria, Barcelona, N. Ramírez.

CAJA CATALANA MERCANTIL E INDUSTRIAL (1858): Memoria, Barcelona, Pons y Cía.

CARRERAS, Albert (1990): Industrialización española: estudios de historia cuantitativa, Madrid, Espasa-Calpe.

CARRERAS, Albert, y TAFUNELL, Xavier (2005) (eds.): Estadísticas Históricas de España. Siglos XIX y XX, Bilbao, Fundación BBVA.

FERNÁNDEZ PULGAR, Carlos, y ANES, Rafael (1970): “La creación de la peseta en la evolución del sistema monetario de 1847 a 1865", en SCHWARTZ, Pedro (ed.), Ensayos sobre la economía española a mediados del siglo XIX, Madrid, Banco de España, pp. 147-186.

FIGUEROLA, Laureano (1983 [1849-1851]): Estadística de Barcelona en 1849, Barcelona, Alta Fulla.

GARRABOU, Ramon, y PUJOL, Josep (1987): “El canvi agrari a la Catalunya del segle XIX", Recerques 19. Homenatge a Pierre Vilar, vol. I, pp. 35-83.

JAUMEANDREU, Eudald (1988 [1816]): Rudimentos de economía politica, Barcelona, Editorial Alta Fulla.

-(1836): Curso elemental de economía política..., I, Barcelona, Imprenta de Gaspar.

KING, Robert G., y LEVINE, Ross (1993): "Finance and growth: Schumpeter might be right", Quarterly Journal of Economics, 108, pp. 717-738.

LEVINE, Ross (2005): "Finance and growth: theory and evidence", en AGHION, Philippe, y DURLAUF, Steven N. (eds.), Handbook of Economic Growth, vol. 1A, Elsevier B.V., Amsterdam, pp. 865-934.

LLUCH, Ernest (1973): El pensament econòmic a Catalunya (1760-1840). Els orígens ideològics del proteccionisme i la presa de consciència de la burgesia catalana, Barcelona, Edicions 62.

MALUQUER DE MOTES, Jordi (2001): "Cataluña, avanzada de la industrialización”, en GERMÁN, Luis; LLOPIS, Enrique; MALUQUER DE MOTES, Jordi, y ZAPATA, Santiago (eds.), Historia económica regional de España, siglos XIX y XX, Crítica, Barcelona, pp. 357-389.

-(2006): “'La paradisíaca estabilidad de la anteguerra'. Elaboración de un índice de precios de consumo en España, 1830-1936", Revista de Historia Económica, XXIV, 2, pp. 333-382. 
NADAL, Jordi (1992): “Cataluña, la fábrica de España. La formación de la industria moderna en Cataluña", en NADAL, Jordi (ed.), Moler, tejer y fundir. Estudios de historia industrial, Barcelona, Ariel, pp. 84-154.

NAVAS, Manuel, y SUDRIÀ, Carles (en prensa): “La crisi financera de 1866 a Barcelona. Una revisió", Recerques.

PASCUAL, Pere (1990): Agricultura i industrialització a la Catalunya del segle XIX, Barcelona, Crítica.

-(1999): Los caminos de la era industrial. La construcción y financiación de la Red Catalana de Ferrocarriles (1843-1898), Barcelona, Edicions Universitat de Barcelona/Fundación de los Ferrocarriles Españoles.

-(2004): "Moneda e industria. La reforma de 1824 y la acuñación de moneda en Barcelona (1836-1848)", Revista de Historia Industrial, 26, pp. 57-99.

-(2007): “La Diputació i la construcció de la xarxa catalana de carreteres: 18401868", en RIQUER, Borja de (ed.), Història de la Diputació de Barcelona, I, Barcelona, Diputació de Barcelona, pp. 152-211.

RAVENTÓS, Manuel (1938): “Notes sobre el diner espanyol en el segle XIX (II)", Revista de Catalunya, 86, pp. 55-76.

ROCKOFF, Hugh (1975): The Free Banking Era: A Reexamination, Nueva York, Arno Press.

ROUSSEAU, Peter L. (2007): "Backing, the Quantity Theory, and the Transition to the US Dollar, 1723-1850", American Economic Review, 97 (2), pp. 266-270.

ROUSSEAU, Peter L., y SYLLA, Richard (2003): "Financial systems, economic growth, and globalization", en BORDO, Michel D.; TAYLOR, Alan M., y WILLIAMSON, Jeffrey G. (eds.), Globalization in Historical Perspective, University of Chicago Press, Chicago, pp. 373-415.

-(2006): "Financial revolutions and economic growth: Introducing this EEH symposium", Explorations in Economic History, 43, pp. 1-12.

SÁNCHEZ-ALBORNOZ, Nicolás (1963), “La crisis de 1866 en Barcelona (notas para su estudio)", en Homenaje a D. Ramón Carande, Madrid, pp. 421-436.

-(1977): España hace un siglo: una economía dual, Madrid, Alianza Editorial.

SANTILLÁN, Ramón (1982 (1865)): Memoria histórica sobre los bancos Nacional de San Carlos, Español de San Fernando, Isabel II, nuevo de San Fernando y de España, Madrid, Banco de España.

SARDÁ, Juan (1948): La política monetaria y las fluctuaciones de la economía española en el siglo XIX, Madrid, CSIC.

SUDRIÂ, Carles (1982): “Desarrollo industrial y subdesarrollo bancario en Cataluña, 1844-1950", Investigaciones Económicas, 18, pp. 137-176.

-(1994): "Capitalistes i fabricants. El finançament de la industrialització catalana (1815-1866)", Butlletí de la Societat Catalana d'Estudis Històrics, V, pp. 29-40.

SUDRIÀ, Carles, y PASCUAL Pere (1999): “Financing a railway mania: capital for- 
mation and the demand for money in Catalonia, 1840-66", Financial History Review, 6 (2), pp. 127-145.

TAFUNELL, Xavier (1991): "Banca i mercat de capitals, 1866-1914", en NADAL, Jordi; MALUQUER DE MOTES, Jordi; SUDRIÂ, Carles, y CABANA, Frencesç (dirs.), Història Econòmica de la Catalunya contemporània. s. XIX. 3. Indústria, transports i finances, Barcelona, Enciclopèdia Catalana, pp. 379-385.

TEDDE DE LORCA, Pedro (1999): El Banco de San Fernando (1829-1856), Madrid, Banco de España/Alianza Editorial.

TORTELLA, Gabriel (1970): “El Banco de España entre 1829-1929. La formación de un banco central", en BANCO DE ESPAÑA, El Banco de España. Una historia económica, Madrid, Banco de España, pp. 261-313.

-(1973): Los orígenes del capitalismo en España, Madrid, Tecnos.

VALLS, Francesc (2003): La Catalunya atlàntica. Aiguardent i teixits en l'arrencada industrial catalana, Barcelona, Eumo Editorial.

WHITE, Lawrence H. (1984): Free Banking in Britain: Theory, Experience, and Debate, 1800-1845, Cambridge, Cambridge University Press.

WHITE, Lawrence H. (1992) (ed.): Free Banking, 3 vols., Londres, Edward Elgar. 


\section{APÉNDICE}

EVOLUCIÓN MENSUAL DEL CAMBIO DE LOS "BILLETES-CALDERILLA" PUESTOS EN CIRCULACIÓN EN 1852 A RAÍZ DE LA AMORTIZACIÓN DE LA CALDERILLA CATALANA, 1855-1867

(porcentajes sobre el valor nominal)

\begin{tabular}{|c|c|c|c|c|c|c|c|c|}
\hline Año & Mes & Porcentaje & Año & Mes & Porcentaje & Año & Mes & Porcentaje \\
\hline \multirow[t]{12}{*}{1855} & 1 & 94,49 & & 9 & 88,43 & & 5 & 95,54 \\
\hline & 2 & 95,38 & & 10 & 90,03 & & 6 & 95,66 \\
\hline & 3 & 95,16 & & 11 & 89,39 & & 7 & 95,92 \\
\hline & 4 & 93,63 & & 12 & 90,00 & & 8 & 96,07 \\
\hline & 5 & 93,47 & 1858 & 1 & 89,83 & & 9 & 96,99 \\
\hline & 6 & 93,13 & & 2 & 90,19 & & 10 & 97,38 \\
\hline & 7 & 93,00 & & 3 & 91,18 & & 11 & 97,22 \\
\hline & 8 & 92,78 & & 4 & 92,09 & & 12 & 98,25 \\
\hline & 9 & 92,44 & & 5 & 92,50 & 1861 & 1 & 98,25 \\
\hline & 10 & 92,35 & & 6 & 93,55 & & 2 & 98,09 \\
\hline & 11 & 91,91 & & 7 & 93,61 & & 3 & 98,12 \\
\hline & 12 & 91,41 & & 8 & 94,00 & & 4 & 98,38 \\
\hline \multirow[t]{12}{*}{1856} & 1 & 90,07 & & 9 & 93,89 & & 5 & 98,38 \\
\hline & 2 & 91,38 & & 10 & 93,83 & & 6 & 98,21 \\
\hline & 3 & 92,00 & & 11 & 93,83 & & 7 & 98,32 \\
\hline & 4 & 91,00 & & 12 & 93,83 & & 8 & 98,45 \\
\hline & 5 & 91,49 & 1859 & 1 & 93,69 & & 9 & 98,49 \\
\hline & 6 & 91,56 & & 2 & 93,78 & & 10 & 98,68 \\
\hline & 7 & 91,88 & & 3 & 93,78 & & 11 & 98,68 \\
\hline & 8 & 91,49 & & 4 & 93,67 & & 12 & 98,61 \\
\hline & 9 & 91,08 & & 5 & 91,35 & 1862 & 1 & 98,58 \\
\hline & 10 & 90,88 & & 6 & 92,63 & & 2 & 98,42 \\
\hline & 11 & 89,00 & & 7 & 92,05 & & 3 & 98,49 \\
\hline & 12 & 88,49 & & 8 & 92,49 & & 4 & 98,45 \\
\hline \multirow[t]{8}{*}{1857} & 1 & 89,13 & & 9 & 92,37 & & 5 & 98,25 \\
\hline & 2 & 88,67 & & 10 & 93,28 & & 6 & 98,15 \\
\hline & 3 & 88,28 & & 11 & 93,37 & & 7 & 98,13 \\
\hline & 4 & 88,03 & & 12 & 95,07 & & 8 & 98,13 \\
\hline & 5 & 87,78 & 1860 & 1 & 95,05 & & 9 & 98,13 \\
\hline & 6 & 87,86 & & 2 & 95,93 & & 10 & 98,13 \\
\hline & 7 & 88,18 & & 3 & 95,89 & & 11 & 98,13 \\
\hline & 8 & 88,15 & & 4 & 95,88 & & 12 & 98,03 \\
\hline
\end{tabular}




\section{APÉNDICE}

EVOLUCIÓN MENSUAL DEL CAMBIO DE LOS "BILLETES-CALDERILLA" PUESTOS EN CIRCULACIÓN EN 1852 A RAÍZ DE LA AMORTIZACIÓN DE LA CALDERILLA CATALANA, 1855-1867 (continuación)

(porcentajes sobre el valor nominal)

\begin{tabular}{|c|c|c|c|c|c|c|c|c|}
\hline Año & Mes & Porcentaje & Año & Mes & Porcentaje & Año & Mes & Porcentaje \\
\hline \multirow[t]{12}{*}{1863} & 1 & 98,03 & & 10 & 98,00 & & 7 & 92,59 \\
\hline & 2 & 97,95 & & 11 & 97,92 & & 8 & 92,75 \\
\hline & 3 & 97,95 & & 12 & 97,88 & & 9 & 92,75 \\
\hline & 4 & 97,95 & 1865 & 1 & 94,74 & & 10 & 92,75 \\
\hline & 5 & 97,95 & & 2 & 94,00 & & 11 & 92,75 \\
\hline & 6 & 97,95 & & 3 & 95,42 & & 12 & 93.44 \\
\hline & 7 & 97,88 & & 4 & 93,19 & 1867 & 1 & 95,00 \\
\hline & 8 & 97,88 & & 5 & 95,82 & & 2 & 95,07 \\
\hline & 9 & 97,98 & & 6 & 94,59 & & 3 & 94,95 \\
\hline & 10 & 97,98 & & 7 & 94,50 & & 4 & 94,95 \\
\hline & 11 & 97,98 & & 8 & 94,17 & & 5 & 94,92 \\
\hline & 12 & 97,63 & & 9 & 94,50 & & 6 & 95,25 \\
\hline \multirow[t]{9}{*}{1864} & 1 & 97,59 & & 10 & 94,55 & & 7 & 95,13 \\
\hline & 2 & 97,63 & & 11 & 95,98 & & 8 & 95,25 \\
\hline & 3 & 97,69 & & 12 & 95,97 & & 9 & 94,95 \\
\hline & 4 & 97,63 & 1866 & 1 & 95,13 & & 10 & 94,85 \\
\hline & 5 & 98,00 & & 2 & 95,38 & & 11 & 96,35 \\
\hline & 6 & 97,63 & & 3 & 95,50 & & 12 & 96,25 \\
\hline & 7 & 97,79 & & 4 & 95,38 & & & \\
\hline & 8 & 98,00 & & 5 & 91,25 & & & \\
\hline & 9 & 98,05 & & 6 & 92,35 & & & \\
\hline
\end{tabular}

Fuentes: ANC, Fondo Corredors Reials de Canvi de Barcelona, Libro(s) registro de cotizaciones..., para los años comprendidos entre 1855 —en que se inició la anotación del cambio de dicho papel—y 1867. 